\title{
6. ASTRONOMICAL TELEGRAMS (TELEGRAMMES ASTRONOMIQUES)
}

(Committee of the Executive Committee)

PRESIDENT: J. E. Grindlay

VICE-PRESIDENT: R. M. West

ORGANIZING COMMITTEE: S. Isobe, B. G. Marsden, E. Roemer

DIRECTOR OF THE BUREAU: B. G. Marsden, Smithsonian Astrophysical Observatory, 60 Garden Street, Cambridge, MA 02138, U.S.A. (TWX 710-320-6842 ASTROGRAM CAM, e-mail MARSDEN@CFA.HARVARD.EDU)

ASSOCIATE DIRECTOR OF THE BUREAU: D. W. E. Green

\section{INTRODUCTION}

The need for rapid communication of astronomical discoveries continues to increase, as the number of observers able to participate and report rapidly by electronic mail inexorably rises. Both the increased number and power of observatories in space (e.g., HST, ROSAT, CGRO, ASCA) and the increased access to powerful observing and reduction tools for ground-based observations have contributed in a significant way. The past three years (1990-93), or the triennium covered by the present report, has seen the launch of all of the above-named space observatories, so that it has been an especially active period. With long operational lifetimes planned, and the addition of new major satellite-borne observing capabilities (e.g., XTE, ISO, AXAF) planned for the next 3-6 years, this will increase even further. On the ground, the rapid dissemination of CCDs and computer data acquisition (and processing) systems among the amateur astronomical community that has taken place over the past three years is also expected both to increase the rate of discovery of novae and dwarf novae outbursts as well as to provide increased longitudinal and temporal coverage for the increasing number of multi-wavelength monitoring campaigns being carried out. Announcement and coordination of these campaigns, particularly with the satellite observatories, has become an increasingly important function of the Circulars issued by the Central Bureau.

The report of the Central Bureau, given below, charts the increase in Circulars issued and the understandable demise of the telegrams in this era of electronic communication. The Commission owes, once again, a special debt of gratitude to Dr. Brian Marsden for performing such capable service to the entire astronomical community in his role as Director of the Bureau. This year marks the 25th anniversary of the directorship of Dr. Marsden and thus should be noted with even more fanfare than the rapidly approaching issuance of the 6000th Circular. The Commission wishes to thank also Mr. Daniel Green, Associate Director of the Bureau, for his capable assistance to Dr. Marsden and for his proven judgement on publication of a majority of the recent Circulars.

The next triennium promises transient events of great interest that are both predicted (e.g., the periastron passage of the millisecond pulsar PSR 1259-63 into the wind of its Be star companion in January 1994; or the probable impact of comet 1993e with Jupiter in July 1994) and of course only desirable (e.g., the first identification of a counterpart of a $\gamma$-ray burst source, perhaps after the launch of the HETE satellite in 1994-95). It is certain that the Commission, and the Central Bureau, will have a significant role in the rapid dissemination of these and other discoveries. It may be desirable to augment the membership of the Commission in anticipation of this activity.

J. E. Grindlay

President of the Commission 


\section{REPORT OF THE CENTRAL BUREAU FOR ASTRONOMICAL TELEGRAMS}

During the triennium the Central Bureau issued 'telegram books' and Circulars as follows:

$\begin{array}{lcc} & \text { Telegrams } & \text { Circulars } \\ \text { 1990 July-Dec. } & 16 & \text { Nos. 5046-5152 } \\ \text { 1991 Jan.-June } & 28 & \text { Nos. 5153-5295 } \\ \text { 1991 July-Dec. } & 18 & \text { Nos. 5296-5419 } \\ \text { 1992 Jan.-June } & 16 & \text { Nos. 5420-5551 } \\ \text { 1992 July-Dec. } & 16 & \text { Nos. 5552-5685 } \\ \text { 1993 Jan.-June } & 1 & \text { Nos. 5686-5827 }\end{array}$

Comparison with the report of the previous triennium shows that there has been almost a 25-percent increase in the number of Circulars issued-but a corresponding decrease in the number of telegrams. The fact that only one telegram book was issued after the end of 1992 exaggerates this difference, because the Central Bureau deliberately did not issue any telegrams after 1993 Jan. 5. Some three months later an enquiry was made as to whether the telegrams were actually needed. Most telegram subscribers did not respond, a few thought that to stop the telegrams was an excellent idea, and only one (a U.S. amateur who receives the telegrams by mailgram) felt it necessary that they continue! Clearly, most subscribers are now receiving the complete Circulars themselves by electronic mail, and the often-very-terse telegrams have become prohibitively expensive in comparison to their value. There are still a few important observatories that are outside the electronic-mail circuit, but their number continues to decrease. Accordingly, steps are being taken to discontinue use of the telegrams (except in the titles of the Commission and the Central Bureau!), and any credit remaining in the telegram accounts is being transferred to the corresponding Circulars accounts. The fact that the previous report mentioned that the telegrams "continue to be essential" and that "they are likely to continue to be so for the foreseeable future" merely illustrates the difficulty of making predictions and the speed with which international communication practice has been changing in the aftermath of the Cold War. Although the Central Bureau continues occasionally to receive information by telegram (as opposed to e-mail), there seems now no point in going forth with the promised reprinting of the telegraphic code from IAU Inf. Bull. No. 46 (1981).

Scientifically, most of the material handled by the Central Bureau continues to be in the four traditional areas of comets, earth-approaching minor planets, novae and supernovae. Records for the number of supernovae were broken successively in 1990, 1991 and 1992 (with 72 objects designated in that year), but the discovery rate was noticeably less in 1993. A dozen galactic novae appeared in less than two years, and 1991 had record numbers of comets and near-earth asteroids. Beginning with the discovery of (5145) Pholus in early 1992 there has been an extraordinary surge of interest in objects in the outer solar system, including two that appear to be in stable orbits entirely beyond Neptune.

Concern has been voiced about the decreasing number of actual subscribers to the Central Bureau's services and the indiscriminate redistribution of the electronic versions of the Circulars on computer bulletin boards. Paid subscriptions are necessary for the continuation of the service, and some astronomers-professional and amateur-have rallied to the cause. The number of subscribers to the printed Circulars seems to have stabilized at a little more than 700 , and of these some 250 also subscribe electronically, an increase by some 20 percent during the past year.

B. G. Marsden

Director of the Bureau 